\title{
Acute lymphoid leukemia developing in the course of Crohn's Disease: Are there any guilty
} agents?

\author{
Nergiz Ekmen', Güray Can ${ }^{2}$, Hadi Sasani ${ }^{3}$ \\ ${ }^{1}$ Department of Gastroenterology, Faculty of Medicine, Gazi University, Ankara, Turkey \\ ${ }^{2}$ Department of Gastroenterology, Faculty of Medicine, Abant Izzet Baysal University, Bolu, Turkey \\ ${ }^{3}$ Department of Radiology, Faculty of Medicine, Tekirdag Namık Kemal University, Tekirdağ, Turkey
}

Received: 2021-04-07.

Accepted: 2021-05-04

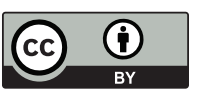

This work is licensed under a

Creative Commons Attribution 4.0 International License
J Clin Med Kaz 2021; 18(3):65-67

Corresponding author:

Nergiz Ekmen.

E-mail: dr nergisekmen@hotmail.com; ORCID: $0000-0002-7921-3169$

\section{Abstract}

Anti-tumor necrosis factor-alpha drugs (anti-TNF- $\alpha$ ), which are monoclonal antibodies, have revolutionized the treatment of severe and refractory inflammatory bowel disease in the last two decades. However, these drugs pose a risk for the formation of hematological malignancies such as lymphoma and acute leukemia. To our knowledge, acute lymphoblastic leukemia has been reported in the literature in only two Crohn's patients with a history of anti-TNF- $\alpha$ therapy.

In this article, we reported a case of Philadelphia chromosome positive acute lymphoid leukemia occurring during the course of disease with a history of azathioprine and anti-TNF- $\alpha$ treatment with the diagnosis of Crohn's disease. In addition, we wanted to emphasize that the patient was followed up in remission for five years after allogeneic bone marrow transplantation although he did not receive treatment for Crohn's disease.

Key words: acute lymphoid leukemia, inflammatory bowel disease, anti-tumor necrosis factor-alpha drugs

\section{Introduction}

Crohn's disease is a chronic inflammatory gastrointestinal system disease of unknown etiology that causes deterioration in the patient's quality of life [1]. A chimeric immunoglobulin monoclonal antibody [anti-tumor necrosis factor alpha (anti-TNF- $\alpha$ )] drugs that neutralize the biological activity of TNF- $\alpha$ have revolutionized the treatment approach of inflammatory bowel disease (IBD) patients with severe or refractory disease in the last two decades [2-4]. However, these drugs pose a risk as a cause of triggering and/or emergence of various malignancies. In recent years, after various anti-TNF- $\alpha$ treatments, hematological malignancies such as lymphoma, acute myeloid leukemia and fewer hematological malignancies such as acute lymphoid leukemia have been reported [5].

We aimed to report a Philadelphia chromosome positive acute lymphoid leukemia [Ph (+) ALL] patient after the use of infliximab and azathioprine for the treatment of severe Crohn's disease.

\section{Case presentation}

A 22-year-old male patient without a known disease was diagnosed with Crohn's disease with complaints of abdominal pain and weight loss, ileocolonoscopy images and histopathological findings of colonoscopic biopsy. Azathioprine treatment was started in the patient who was A2-L3-P (A2, between 17 and 40 years; L3, ileocolonic; $\mathrm{P}$, perianal disease) according to the Montreal classification [6]. Infliximab $5 \mathrm{mg} / \mathrm{kg}$ was started as fistulas did not regress in 10 months of follow-up and Crohn's Disease Activity Index was above 150. Clinical response was obtained and perianal fistulas closed, after 3 months of this treatment.

In blood tests, erythrocyte sedimentation rate and C-reactive protein, leukocyte and platelet counts were also found to be normal. However, it was seen that ileocolonic ulcers continued in endoscopic control (Figure 1). Azathioprine was discontinued after 10 months alone and 9 months in combination with infliximab. Skin lesions compatible with leukocytoclastic vasculitis appeared in the feet after using infliximab treatment for 23 months. Since this situation was thought to be related to infliximab, the patient was in clinical and biochemical remission, and infliximab treatment was discontinued. Aphthous ulcers in the colon were observed to persist in the colonoscopy performed while infliximab was discontinued (Figure 2). While C-reactive protein increased progressively during the 
Figure 1 - Colonoscopy findings in a patient under infliximab and azathioprine treatment: (A, B) arrows show aphthous ulcers on the colon mucosa, $(\mathrm{C})$ shows exudative ulcers at the level of the ileocecal valve (arrow).

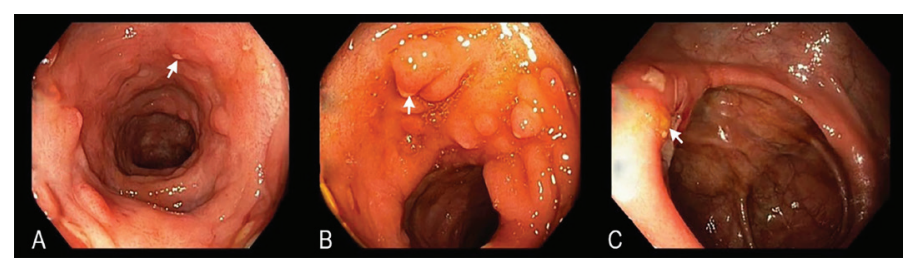

Figure 2 - Endoscopic findings in colonoscopy after infliximab discontinuation. (A) Normal mucosal areas in the terminal ileum, $(B, C, D)$ showing aphthous ulcers in the colon.

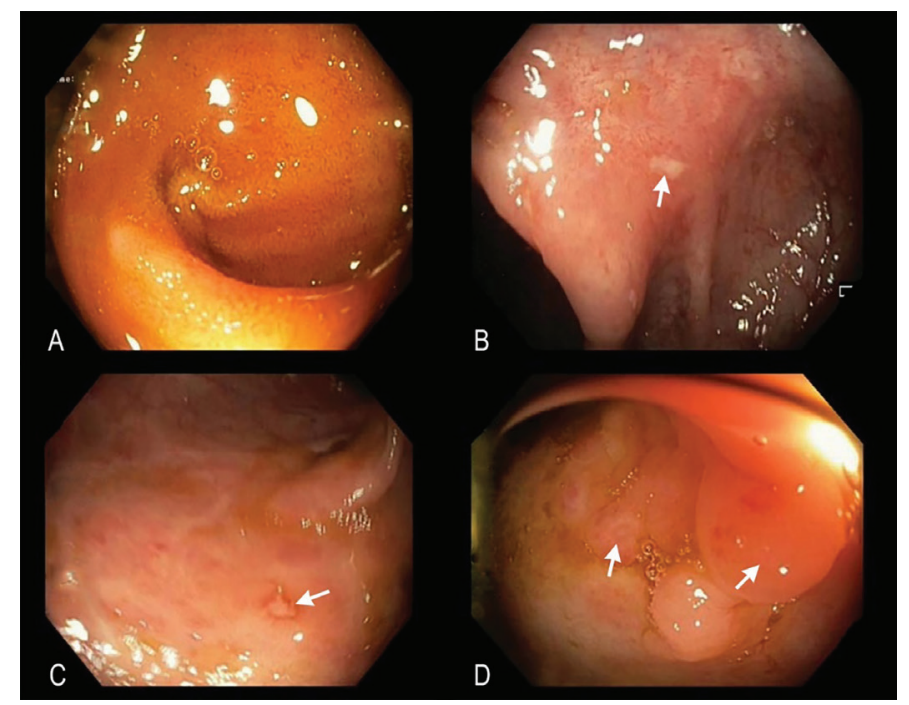

Figure 3 - Lymph nodes in the neck, mediastinum (arrows) and Lymphadenopathies in the axillary region (arrow heads).

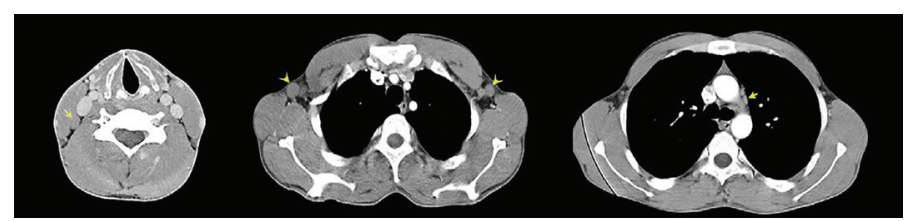

14-month follow-up without treatment, complaints of weight loss and abdominal pain occurred.

Adalimumab treatment was planned for the patient who did not accept colonoscopic examination. Three weeks after adalimumab treatment leukocytosis [32400/mm3 (80.5\% lymphocytes)], thrombocytopenia $(41000 / \mathrm{mm} 3)$ and anemia ( $9 \mathrm{gr} / \mathrm{dL})$ were observed in hemogram analysis. On physical examination, lymphadenopathies in the neck and bilateral inguinal region were detected. Pathological lymphadenomegalies were observed in the neck, thorax and abdominal CT scans (Figure 3). The hematologist detected blastic cells in the peripheral smear. Cytogenetic procedure was performed with bone marrow aspiration and biopsy upon these findings. Cytogenetic examination revealed Philadelphia chromosome, and a diagnosis of $\mathrm{Ph}(+)$ ALL was made by bone marrow biopsy. After a total of 2 cycles of Hyper-CVAD chemotherapy (including cyclophosphamide, vincristine sulfate, Adriamycin and dexamethasone), remission was achieved and the patient was transplanted with haploidentic stem cell transplantation from his father, since he was not a fully compatible human leukocyte antigen (HLA) sibling donor. The patient, who has not received treatment for Crohn's disease for 5 years, is in remission and is followed up by hematology and gastroenterology outpatient clinics.

\section{Discussion}

To our best knowledge, three cases of acute lymphoblastic leukemia have been reported so far with Infliximab [7-9]. A 40-year-old patient followed by Özdemirkiran et al. has a 10-year history of ankylosing spondylitis. This patient was diagnosed with $\mathrm{Ph}(+)$ ALL after using indomethacin and sulfasalazine for 9 years, followed by infliximab and adalimumab for 10 months each. A 62-year-old patient reported by Cessani et al. has a 23 years' history of Crohn's disease. This patient was diagnosed with $\mathrm{Ph}(+)$ ALL after 14 years of frequent use of steroids with azathioprine and only 4 months of adalimumab use. The 40 -yearold patient reported by Alcain et al. has only a 4-year history of Crohn's disease. This patient could not use azathioprine treatment due to gastrointestinal intolerance, and infliximab treatment was initiated when she was unresponsive to the treatment after short-term methotrexate use. She was diagnosed with $\mathrm{Ph}(+)$ ALL after only 1.5 months of infliximab use. It is noteworthy that both $\mathrm{Ph}(+)$ ALL cases reported had a long duration of chronic disease, one had a long anti-inflammatory (salazopyrine) treatment period, and the other received a longterm immunomodulatory (azathioprine) treatment [7, 8]. In the other case, there was a fairly short history of anti-TNF- $\alpha$ and immunomodulatory therapy [9]. The common point of these three cases is the severe course of chronic inflammatory disease and poor response to standard therapy. In long-term safety studies conducted with infliximab and adalimumab, the relationship between anti-TNF- $\alpha$ and hematological malignancies alone could not be demonstrated [10]. In the European Crohn's and Colitis Organization guideline, it is reported that anti-TNF- $\alpha$ alone are not associated with malignancy and the use of azathioprine in IBD increases the risk of lymphoma, especially in Crohn's disease [11]. It has been reported that the risk of T-cell hepatosplenic lymphoma increases especially with the use of azathioprine and anti-TNF- $\alpha$ combination for more than two years [10]. It is stated that the risk of myeloid leukemia increases in the long term with thiopurines [10]. In our case, a total of 23 months of infliximab and 19 months of azathioprine (9 months in combination) was used, and $\mathrm{Ph}(+)$ ALL developed. This patient, like the other three reported patients, shares the common point of severe chronic inflammatory disease and poor response to treatment. Considering these patients, we think that besides the effect of long-term immunomodulators, antiTNF- $\alpha$ and anti-inflammatory drugs, duration of the chronic inflammatory disease and duration of the active disease, poor response to standard treatments, and the severe course of the disease may have an effect on the development of ALL. In addition, it is known that it poses a risk in terms of various malignancies, especially lymphoproliferative disease, even after the treatment is discontinued due to DNA damage that occurs during the period when immunomodulators are used, and this risk is multiplied when anti-TNF is added to the treatment [11]. The fact that he has been in remission for 5 years without treatment after allogeneic bone marrow transplant demonstrates the effectiveness of allogeneic bone marrow transplantation in Crohn's disease [12].

Disclosures: There is no conflict of interest for all authors.

Acknowledgements: None.

Funding: None. 


\section{References}

1. Feuerstein JD, Cheifetz AS. Crohn Disease: Epidemiology, Diagnosis, and Management. Mayo Clin Proc. 2017; 92(7):1088-1103. doi: 10.1016/j.mayocp.2017.04.010.

2. Côté-Daigneault J, Bouin M, Lahaie R, Colombel JF, Poitras P. Biologics in inflammatory bowel disease: what are the data? United European Gastroenterol J. 2015; 3(5):419-28. doi: 10.1177/2050640615590302.

3. Tracey D, Klareskog L, Sasso EH, Salfeld JG, Tak PP. Tumor necrosis factor antagonist mechanisms of action: a comprehensive review. Pharmacol Ther. 2008; 117(2):244-79. doi: 10.1016/j.pharmthera.2007.10.001.

4. Plevy SE, Landers CJ, Prehn J, Carramanzana NM, Deem RL, Shealy D, et al. A role for TNF-alpha and mucosal T helper-1 cytokines in the pathogenesis of Crohn's disease. J Immunol. 1997; 159(12):6276-82.

5. Askling J, Fored CM, Baecklund E, Brandt L, Backlin C, Ekbom A, et al. Haematopoietic malignancies in rheumatoid arthritis: lymphoma risk and characteristics after exposure to tumour necrosis factor antagonists. Ann Rheum Dis. 2005; 64(10):1414-20. doi: 10.1136/ard.2004.033241.

6. Satsangi J, Silverberg MS, Vermeire S, Colombel JF. The Montreal classification of inflammatory bowel disease: controversies, consensus, and implications. Gut. 2006; 55(6):749-53. doi: 10.1136/gut.2005.082909.

7. Cesarini M, Vernia P, Angelucci E. Acute lymphoid leukemia in a Crohn's disease patient during treatment with adalimumab after a prolonged treatment with azathioprine and steroids. Inflamm Bowel Dis. 2010; 16(3):371-2. doi: 10.1002/ibd.21005.

8. Özdemirkiran FG, Payzin BK, Çoban E, Bayram KB, Küçükzeybek B. Acute lymphoid leukemia after anti-TNF-alpha treatment: a case report and review of the literature. Turk J Rheumatol. 2015; 30:349-52. DOI: 10.5606/ArchRheumatol.2015.5669.

9. Alcaín G, Andrade RJ, Queipo de Llano MP, Moreno MJ, García-Cortés M, Franquelo E. Acute leukemia after infliximab therapy. Am J Gastroenterol. 2003; 98(11):2577. doi: 10.1111/j.1572-0241.2003.08682.x.

10. Annese V, Beaugerie L, Egan L, Biancone L, Bolling C, Brandts C, et al. ECCO. European Evidence-based Consensus: Inflammatory Bowel Disease and Malignancies. J Crohns Colitis. 2015; 9(11):945-65. doi: 10.1093/ecco-jcc/jjv141.

11. Torres J, Bonovas S, Doherty G, Kucharzik T, Gisbert JP, Raine T, et al. ECCO Guidelines on Therapeutics in Crohn's Disease: Medical Treatment. J Crohns Colitis. 2020; 14(1):4-22. doi: 10.1093/ecco-jcc/jjz180.

12. Oliveira MC, Elias JB, Moraes DA, Simões BP, Rodrigues M, Ribeiro AAF, et al. A review of hematopoietic stem cell transplantation for autoimmune diseases: multiple sclerosis, systemic sclerosis and Crohn's disease. Position paper of the Brazilian Society of Bone Marrow Transplantation. Hematol Transfus Cell Ther. 2021; 43(1):65-86. doi: 10.1016/j.htct.2020.03.002. 